\title{
Interventions in WNT Signaling to Induce Cardiomyocyte Proliferation: Crosstalk with Other Pathways
}

\author{
W. Matthijs Blankesteijn \\ Department of Pharmacology and Toxicology, Cardiovascular Research Institute Maastricht, Maastricht University, The \\ Netherlands
}

Received August 5, 2019; accepted November 6, 2019

\section{ABSTRACT}

Myocardial infarction is a frequent cardiovascular event and a major cause for cardiomyocyte loss. In adult mammals, cardiomyocytes are traditionally considered to be terminally differentiated cells, unable to proliferate. Therefore, the woundhealing response in the infarct area typically yields scar tissue rather than newly formed cardiomyocytes. In the last decade, several lines of evidence have challenged the lack of proliferative capacity of the differentiated cardiomyocyte: studies in zebrafish and neonatal mammals have convincingly demonstrated the regenerative capacity of cardiomyocytes. Moreover, multiple signaling pathways have been identified in these models that-when activated in adult mammalian cardiomyocytes -can reactivate the cell cycle in these cells. However, cardiomyocytes frequently exit the cell cycle before symmetric division into daughter cells, leading to polyploidy and multinucleation. Now that there is more insight into the reactivation of the cell cycle machinery, other prerequisites for successful symmetric division of cardiomyocytes, such as the control of sarcomere disassembly to allow cytokinesis, require more investigation. This review aims to discuss the signaling pathways involved in cardiomyocyte proliferation, with a specific focus on wingless/int-1 protein signaling. Comparing the conflicting results from in vitro and in vivo studies on this pathway illustrates that the interaction with other cells and structures around the infarct is likely to be essential to determine the outcome of these interventions. The extensive crosstalk with other pathways implicated in cardiomyocyte proliferation calls for the identification of nodal points in the cell signaling before cardiomyocyte proliferation can be moved forward toward clinical application as a cure of cardiac disease.

\section{SIGNIFICANCE STATEMENT}

Evidence is mounting that proliferation of pre-existing cardiomyocytes can be stimulated to repair injury of the heart. In this review article, an overview is provided of the different signaling pathways implicated in cardiomyocyte proliferation with emphasis on wingless/int-1 protein signaling, crosstalk between the pathways, and controversial results obtained in vitro and in vivo.

\section{Introduction}

Diseases of the heart are among the most common causes of morbidity and mortality in man. These diseases include disturbances in cardiac rhythm, contractility, and output, and, despite their highly variable etiology, all result in a loss of pump function to a point where the cardiac output is insufficient to meet the needs of the body. Loss of cardiomyocytes (CMs) generally is considered to be a common contributing factor to the impaired pump function. This becomes particularly apparent after myocardial infarction (MI), wherein many CMs in the infarct area are lost because of an acute interruption of the blood supply.

\footnotetext{
https://doi.org/10.1124/mol.119.118018.
}

Replenishing of the lost CMs has for many years been proposed as the holy grail to repair the damaged heart. To achieve this, the injection of (stem) cells derived from multiple sources has been thoroughly explored, particularly in a context of MI. Unfortunately, the beneficial effects of cell delivery to the infarcted heart have turned out to be disappointing in a clinical setting because of the poor engraftment of the cells in the cardiac tissue as well as issues with immaturity and induction of arrhythmias (Braunwald, 2018).

More recently, the stimulation of endogenous repair mechanisms has been brought forward as a novel approach to repairing cardiac damage. Evidence is mounting that the dogma that adult CMs cannot proliferate may not be true (Bergmann et al., 2009;

ABBREVIATIONS: AAV9, adeno-associated virus 9; AKT, protein kinase B; BIO, 6-bromoindirubin-3'-oxime; BrdU, bromodeoxyuridine; CK1, casein kinase-1; CM, cardiomyocyte; DKK, Dickkopf; ERK, extracellular receptor kinase; FSTL-1, follistatin-like 1; GH, growth hormone; GSK3, glycogen synthase kinase-3; IGF, insulin-like growth factor; LRP, lipoprotein-related receptor protein; MAPK, mitogen-activated protein kinase; MI, myocardial infarction; NRG-1, neuregulin-1; Notum1b, palmitoleoyl-protein carboxylesterase 1b; PI3K, phosphoinositide 3-kinase; sFRP, soluble Frizzled-related protein; TAZ, transcriptional coactivator with PDX-binding motif; TCF/LEF, T-cell factor/lymphoid enhancer-binding factor; Wif1, WNT inhibitory factor 1; WNT, wingless/int-1 protein; YAP, yes-associated protein. 
Bergmann, 2019). Moreover, an increasing number of studies have shown that activation of a variety of signaling pathways can in fact reactivate the cell cycle in CMs past the point of cytokinesis, yielding symmetric division into two daughter cells (Ponnusamy et al., 2017). In this review, we provide an overview of studies in which interventions in wingless/int-1 protein (WNT) signaling result in CM proliferation and cardiac regeneration. These findings will be placed in a context of several other signaling pathways implicated in CM proliferation to identify crosstalk between the pathways and nodal points that are critical in its control.

Wound-Healing Response Following Myocardial Infarction. Cardiac injury following MI evokes a woundhealing response very similar to skin wound healing, as previously described in detail (Cleutjens et al., 1999). Initially, polymorphonuclear neutrophils invade the infarct area somewhere between 6 and 12 hours after the onset of the ischemia, in which they commence with the clearing of the necrotic debris. The necrotic tissue is replaced by granulation tissue rich in (myo)fibroblasts, macrophages, and immature blood vessels embedded in newly formed and relatively unorganized extracellular matrix. In the weeks following the ischemic event, the granulation tissue matures; the number of blood vessels and myofibroblasts decrease, the macrophages disappear, and the amount of deposited extracellular matrix increases to form a scar (van den Borne et al., 2010). Remarkably, however, myofibroblasts remain present in a well-healed cardiac scar to maintain the integrity of the matrix and prevent excessive dilatation of the scar, although the presence of myofibroblasts in the viable myocardium can contribute to stiffness and impairs diastolic function of the ventricles (Hermans et al., 2016).

In the past decade, it has become increasingly clear that the epicardium plays a pivotal role during cardiac development and repair. Using lineage-tracing techniques, epicardial cells have been shown to contribute to vascular smooth muscle cells, pericytes, and fibroblasts in the injured heart. Moreover, the epicardium has been identified as a rich source of signaling molecules that can modulate the wound-healing response and may even stimulate proliferation of CMs around the infarct area. In contrast, the contribution of epicardial cells to the pool of CMs is considered to be minimal (Cao and Poss, 2018). This observation illustrates that the wound healing post-MI involves complex crosstalk between different cells and structures in and around the infarct area. In this review, the question will be addressed whether interventions in this crosstalk can stimulate resident $\mathrm{CMs}$ in the border zone to proliferate, thereby reducing the size of the infarct and improving the cardiac function that was impaired by the injury.

Evidence for Cardiomyocyte Proliferation. Adult mammalian $\mathrm{CMs}$ are generally viewed as terminally differentiated, postmitotic cells that have lost their ability to proliferate during maturation (Zak, 1973). Instead, the typical response of the heart to an increased workload or injury is through cardiac hypertrophy, in which an enlargement of the CMs, rather than a higher number of these cells, is responsible for the adaptation of the heart (Günthel et al., 2018). The contribution of resident cardiac progenitor cells to cardiac regeneration has been proposed in the past but is now considered irrelevant (Eschenhagen et al., 2017)., Several lines of evidence have recently challenged the dogma that
CM proliferation is completely absent in the adult heart and that these cells cannot be directed toward a proliferative state to repair the injured heart, as schematically summarized in Fig. 1.

First of all, CMs of all vertebrates-including humansshow extensive proliferation during the looping phase of the developing heart tube, leading to the ballooning of the ventricles and formation of the four-chambered heart. Moreover, the heart tube is formed by cells migrating from the primary and secondary heart field, and these cells temporarily stop proliferating when the heart tube is formed but then commence their proliferation (Günthel et al., 2018). Taken together, these findings indicate that in embryonal vertebrates, nonproliferating CMs can re-enter the cell cycle, provided that they receive the appropriate signals from their environment. In this context, it is relevant to note that $\mathrm{CM}$ regeneration in response to cardiac injury has also been observed in fetal and neonatal mice (Lam and Sadek, 2018). However, injuries inflicted to mouse hearts later than 1 week after birth lead to scarring rather than CM proliferation, suggesting that the regenerative capacity of the heart is lost shortly after birth (Foglia and Poss, 2016). The postnatal rise in oxygen content has been proposed to induce the cell cycle arrest of the CMs (Puente et al., 2014). This concept is supported by the observation that gradual exposure to severe hypoxia can re-active mitosis in the CMs in the adult mouse heart (Nakada et al., 2017).

A second line of evidence for proliferation of adult $\mathrm{CMs}$ was found in teleost fish (e.g., zebrafish) and some urodele amphibians (e.g., red-spotted newt). Upon resection of the ventricular apex, these animals show full regeneration of cardiac tissue that is populated with $\mathrm{CMs}$ that are functionally coupled to the remaining myocardium (Poss et al., 2002; Witman et al., 2011). Similar results were obtained in a zebrafish cryoinjury model, though in this model the damaged CMs initially were replaced by scar tissue before the area was repopulated with CMs (González-Rosa et al., 2011). Lineagetracing experiments have shown that these newly formed CMs are actually derived from pre-existing, differentiated $\mathrm{CMs}$ rather than from stem or progenitor cells (Jopling et al., 2010).

CM proliferation is not restricted to animal models, such as zebrafish or neonatal mice, but has also been reported to occur in adult humans. In a landmark study, Bergmann et al. made use of the peak in the atmospheric ${ }^{14} \mathrm{C}$ concentration due to aboveground nuclear bomb testing in the 1950s, which dropped dramatically after banning these practices in 1963 . This peak allowed them to carbon-date the DNA in left ventricular myocytes. The authors concluded that there was a $1 \% \mathrm{CM}$ turnover in young adults, which gradually declined to $\sim 0.5 \%$ in 75 -year-olds, with an estimated $45 \%$ of CMs being generated after birth in a 50-year-old person (Bergmann et al., 2009). At present, it is unclear whether cardiac injury can augment CM proliferation in adult humans. It is obvious, however, that this response is inadequate to completely repair cardiac damage as, for example, observed in adult zebrafish.

A complicating factor in the study of CM proliferation is the tendency of these cells to develop polyploidy and multinucleation. Multinucleation is a common event in CMs after birth, with $\sim 90 \%$ binucleation in adult rodents and an increase of ploidy with age in humans. This suggests that adult CMs, 


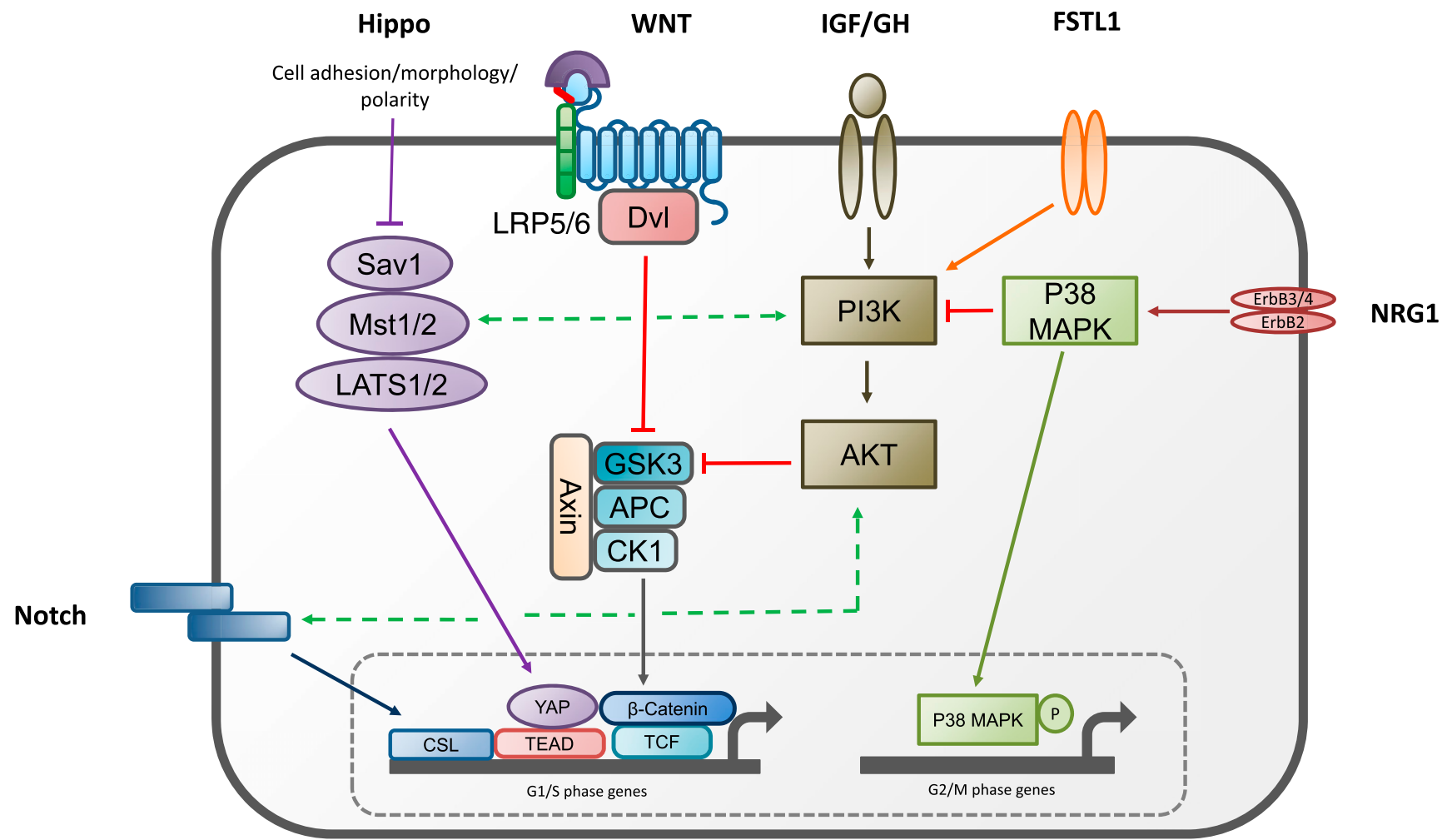

Fig. 1. Schematic representation of the different responses to cardiac injury: In newborn mammals and zebrafish, complete regeneration of the cardiac tissue (purple) has been reported, whereas the wound-healing response in adult mammals typically yields scar tissue (blue). The proregenerative interventions described in this review typically aim at shifting the balance from scar formation toward cardiac regeneration. This results in smaller infarcts and less dilatation of the left ventricle. The black arrow heads point at regions in the infarct where cardiomyocytes were detected, which may reflect the induction of cardiac regeneration by proregenerative interventions. Please note that the histologic sections used to illustrate cardiac regeneration are taken from adult mouse hearts.

though capable of entering the cell cycle, infrequently complete this process with cytokinesis to yield two mononucleated daughter cells (Ponnusamy et al., 2017). Multinucleation and polyploidy are indicators of permanent cell cycle withdrawal, but at present it is unclear whether these processes actively inhibit cell cycle completion by cytokinesis (Yuan and Braun, 2017) or whether an aberrant microtubule distribution in the CM leads to binucleation rather than proper cell division (Leone et al., 2018).

Current detection techniques of cell proliferation, such as detection of mitotic figures, incorporation of labeled DNA building blocks [e.g., bromodeoxyuridine (BrdU)], or immunohistochemical detection of cell cycle markers (e.g., Ki67 or Aurora B kinase), insufficiently discriminate true CM proliferation from multinucleation events (Ponnusamy et al., 2017). It is important to note that degradation of the contractile apparatus of the CM is required for the completion of the cell cycle with cytokinesis to yield two daughter cells (Jopling et al., 2010; Szibor et al., 2014). Novel methods have recently been proposed to identify true CM proliferation, including midbody positioning combined with a correct spacing of the daughter nuclei (Hesse et al., 2018), CM-specific expression of fluorescence ubiquitination-based cell cycle indicator (Alvarez et al., 2019) and multiple-isotope mass spectrometry (Senyo et al., 2013). Using the latter technique, Senyo et al. calculated that $\sim 3.2 \%$ of the CMs around the infarct area had undergone division at 8 weeks post-MI in mice (Senyo et al., 2013), indicating that proliferation of these cells actually can occur in response to cardiac ischemia.

\section{Molecular Control of Cardiomyocyte Proliferation}

The intriguing capacity of zebrafish for cardiac regeneration has stimulated investigations into the molecular pathways inducing CM proliferation in the area of injury. There is a growing body of evidence that interventions in WNT signaling can induce cardiac regeneration. However, WNT signaling does not operate in isolation, as multiple signaling pathways have been implicated in the regenerative response of zebrafish. Follistatin-like 1 (FSTL-1), Hippo/yes-associated protein (YAP)/transcriptional coactivator with PDX-binding motif (TAZ), neuregulin, and Notch signaling appear to be the most important in this respect. These pathways have been investigated in mammalian models of cardiac remodeling, mostly MI. In the following paragraphs, an overview of the literature on WNT signaling in cardiac regeneration will be presented. Subsequently, evidence for the involvement of FSTL-1, Hippo/YAP/TAZ, neuregulin, and Notch signaling in cardiac regeneration will be discussed briefly. The potential nodal points where these pathways can interact will be discussed in the next paragraph.

\section{WNT Signaling}

WNT signaling plays an essential role in developmental biology of a wide variety of animals. A total of 19 different WNT proteins have been identified in mammals, typically 350-400 aa in size. WNT proteins undergo extensive posttranslational modification to become biologically active: 
$N$-linked glycosylation and lipid modification at two distinct sites in the protein. Palmitoleoylation by an enzyme called Porcupine is essential for transportation of WNT proteins to the plasma membrane, where Wntless is responsible for the secretion of WNTs to interact with neighboring cells (MacDonald et al., 2009).

WNT ligands interact with a complex of receptor proteins to activate their intracellular signaling pathways. Originally, proteins from the Frizzled family were identified as receptors for WNT proteins. In the meantime, the involvement of the coreceptors lipoprotein-related receptor protein (LRP) 5 and LRP6 has been firmly established (Schulte, 2010). Several classes of secreted modulators of WNT signaling have been identified, including the members of the Dickkopf (DKK) family. In mammals, this family consists of four members, which - with the exception of DKK3 - can inhibit $\beta$-catenin-mediated WNT signaling by binding to the LRPs with high affinity (Cruciat and Niehrs, 2013).

Upon binding to the receptor complex, WNT proteins can activate distinct signaling pathways. The most extensively studied pathway involves $\beta$-catenin as its second messenger and is frequently referred to as "canonical" WNT signaling. In the inactive state, $\beta$-catenin is phosphorylated by the kinases casein kinase- 1 (CK1) and glycogen synthase kinase-3 (GSK3)- $\beta$, two components of the so-called destruction complex located in the cytoplasm. This phosphorylation is the first step in the degradation of $\beta$-catenin. Activation of the Frizzled/ LRP receptor complex by WNT, however, induces the translocation of the destruction complex to the plasma membrane, where it becomes inactive. The net result of this is an increase in the concentration of cytoplasmic $\beta$-catenin, which can subsequently migrate to the nucleus. There, $\beta$-catenin can associate with transcription factors of the T-cell factor/lymphoid enhancer-binding factor (TCF/LEF) family and induce gene transcription (MacDonald et al., 2009). Next to $\beta$-catenin-mediated signaling, planar cell polarity signaling and signaling via $\mathrm{Ca}^{2+}$ have been described (Schulte, 2010), but their role in cardiac regeneration is only sparsely studied.

In vertebrates, the heart develops from two sets of precursor cells, the first and secondary heart field. After formation of the linear heart tube by cells from the first heart field, mesodermal cells from the secondary heart field migrate toward the tube. The proliferation of the secondary heart field cells is dependent on activation of WNT/ $\beta$-catenin signaling (Günthel et al., 2018). WNT signaling has been shown to form a gradient, which correlates positively with $\mathrm{CM}$ proliferation over the ventricular wall, and activation of $\mathrm{WNT} / \beta$-catenin signaling by deletion of adenomatous polyposis coli protein led to ventricular hyperplasia (Ye et al., 2015). The role of WNT signaling in the development of CMs from embryonic stem cells was shown to be biphasic, depending on the developmental stage: activation of $\mathrm{WNT} / \beta$-catenin signaling is required for mesodermal specification of embryonic stem cells, but further CM differentiation requires the inhibition of WNT/ $\beta$-catenin signaling (Ozhan and Weidinger, 2015). This underscores the complex role of $\mathrm{Wnt} / \beta$-catenin signaling in the differentiation of CMs.

Activation of WNT signaling during infarct healing has not only been demonstrated by studying the changes in expression of its components (Barandon et al., 2003) but also by the use of $\beta$-catenin-sensitive reporter constructs. Using a LacZ reporter mouse under the control of the Axin2 promotor, Oerlemans et al. (2010) reported extensive labeling of endothelial cells, leukocytes, (myo)fibroblasts and stem cells antigen-positive cells. Similar results were obtained in mice where LacZ expression was driven by a TCF/LEF-responsive promotor (Aisagbonhi et al., 2011). Adeno-associated virus 9 (AAV9)mediated transduction of a chimeric probe consisting of human ferritin heavy chain controlled by the TCF/LEF promotor into infarcted rat hearts allowed the detection of $\mathrm{WNT} / \beta$-catenin signaling in the border zone at 4 weeks postMI by magnetic resonance imaging (Matteucci et al., 2016). These studies provide strong support for the activation of WNT signaling in the border zone of the infarct, albeit that the nature of the reporter constructs only allows the detection of WNT/ $\beta$-catenin signaling; the status of the activation of the other WNT signaling pathways after MI is at present less clear.

In Vitro Modulation of WNT Signaling. The importance of WNT/ $\beta$-catenin signaling in embryonic heart development has stimulated many researchers to study the effects of interventions in this pathway on the proliferation and differentiation of various precursor cells toward CMs. Activation of WNT/ $\beta$-catenin signaling in embryonic CMs isolated from the first and secondary heart field showed robust stimulation of the proliferation of these cells (Buikema et al., 2013). Using a chemical screen, Uosaki et al. (2013) identified the GSK3- $\beta$-inhibitor 6-bromoindirubin-3'-oxime (BIO) as a potent inducer of cell cycle markers in mouse pluripotent stem cell-derived CMs. In matured embryonic stem cell-derived CMs, Fan et al. (2018) observed that activation of WNT/ $\beta$-catenin signaling, either by inhibition of GSK3- $\beta$ or by liberating the $N$-cadherin-bound $\beta$-catenin in the cytoplasm. This resulted in increased incorporation of BrdU and increased expression of multiple cyclin genes, suggesting the induction of cell proliferation (Fan et al., 2018).

In several other studies, CMs from neonatal rats were used to study the effect of the activation of WNT/ $\beta$-catenin signaling on their proliferation. Activation of WNT signaling via GSK3- $\beta$ inhibition with BIO $(5 \mu \mathrm{M})$ resulted in a 10 -fold increase in BrdU incorporation and a 5-fold increase in phosphorylated histone-3-positive cells (Tseng et al., 2006). These results were confirmed by Kim et al. (2016), who showed that BIO not only induced BrdU incorporation in cultured neonatal rat CMs but also reduced BrdU incorporation in rat neonatal cardiac fibroblasts. Increased proliferation was also observed in cultured human atrial CMs treated with the GSK3- $\beta$ inhibitor CHIR99021, albeit that the increase in proliferating CMs was modest (control: $1.83 \% \pm 0.01 \%$; CHIR: $2.67 \% \pm 0.08 \%$ ); in this study, inhibition of $\mathrm{WNT} / \beta$-catenin signaling with 4-(1,3,3a,4,7,7a-hexahydro-1,3-dioxo-4,7-methano2H-isoindol-2-yl)-N-8-quinolinyl-benzamide (IWR-1) resulted in a $\sim 35 \%$ reduction in CM proliferation (Wang et al., 2016). Adenoviral-mediated overexpression of $\beta$-catenin in neonatal rat CM, however, showed an initiation of the cell cycle; this did not result in an increased number of CMs but augmented CM hypertrophy and the number of binucleated cells (Hahn et al., 2006). These observations suggest that, though WNT signaling is capable of initiating the cell cycle, other factors are needed to complete the process with cytokinesis.

In Vivo Responses to Modulation of WNT Signaling. In a growing number of studies, the effects of modulation of WNT signaling have been studied in animal models of MI. Here, we will discuss the experimental evidence, starting with interventions at the level of WNT ligand and its extracellular scavenging 
by soluble Frizzled-related proteins (sFRPs), followed by interventions at the level of the receptor complex, intracellular signaling, and modulation of $\beta$-catenin-mediated gene transcription.

Interventions at the Level of WNT. Stimulation of the WNT signaling pathway by increasing the amount of WNT protein in the infarct area has been tested in several studies. The direct injection of WNT3a in the border zone of the infarct resulted in an increased infarct area and reduced cardiac function at 1 week post-MI in mice (Oikonomopoulos et al., 2011). In contrast, beneficial effects on infarct size were reported in mice overexpressing WNT10b in CMs or WNT11 via AAV9-mediated gene transfer. In both studies, this was accompanied by improved pump function of the heart. The proposed mechanisms were an increased neovascularization with reduced fibrosis in the WNT10B overexpression study (Paik et al., 2015) and reduced incorporation of bone marrow-derived inflammatory cells in the AAV9-WNT11 study (Morishita et al., 2016), respectively. It is unclear how the differences between the three studies can be explained, because WNT3a, WNT10b, and WNT11 all have been reported to stimulate $\beta$-catenin-mediated WNT signaling (MacDonald et al., 2009).

An alternative way of intervening in WNT signaling is to inhibit crucial steps in its synthesis or transport to the extracellular space. Attenuation of WNT secretion in macrophages by selectively inactivating the expression of the WNT transporter protein Wntless reduced adverse remodeling and improved cardiac function at 30 days post-MI. This was accompanied by an M2 polarization of the macrophages, which reduces inflammation and promotes angiogenesis and repair (Palevski et al., 2017). Palmitoylation of WNTs is essential for their biologic function (Harterink and Korswagen, 2012), and administration of inhibitors of Porcupine, the enzyme responsible for the attachment of the lipid moiety to WNT proteins, results in the inhibition of the secretion of all WNTs that are expressed in the cell. WNT inhibition with the Porcupine inhibitor GNF-6231, administered intravenously after induction of MI, reduced the infarct size and attenuated the decline in cardiac function at 30 days post-MI. Histologically, fewer apoptotic $\mathrm{CMs}$ were detected and the number of myofibroblasts in the border zone was reduced (Bastakoty and Young, 2016). A similar reduction in infarct size with a concomitant improvement in cardiac function was reported in mice treated systemically with the Porcupine inhibitor WNT-974 from weeks 1 to 10 after MI induction (Moon et al., 2017). The authors conclude, however, that an antifibrotic effect involving collagenVI was responsible for the beneficial effect on infarct healing of WNT-974. In contrast to the studies with Porcupine inhibitors mentioned above, Yang et al. (2017) demonstrated not only reduced infarct size and improved function but also a significant increase in newly formed CMs in the border zone of mice treated with the Porcupine inhibitor CGX1321 for 4 weeks post-MI. The total number of 5-ethynyl-2'-deoxyuridine (EdU)positive mononucleated adult CMs was found to be significantly up-regulated, which was indicative for induction of CM proliferation by the Porcupine inhibitor. Taken together, these studies consistently show that pharmacological inhibition of WNT secretion in the infarct area has beneficial effects on infarct size and cardiac function in vivo.

Modulation at the Receptor Level. Activation of WNT signaling has been convincingly demonstrated during the wound-healing process following MI (Foulquier et al., 2018).
Though several studies have demonstrated the up-regulation of Frizzled proteins during infarct healing (Blankesteijn et al., 1997; Barandon et al., 2003), interventions targeting Frizzled proteins in a model of cardiac ischemia are scarce. Using a 13amino-acid peptide fragment of WNT5a, named UM206, we could demonstrate a reduced infarct size in mice (Laeremans et al., 2011) and swine (Uitterdijk et al., 2016). In mice, this was accompanied by an improved cardiac function and prevention of mortality post-MI. The mechanism of action of this peptide, however, is obscured by its location in the ligandreceptor complex (Janda et al., 2012), making a direct interaction of the peptide with the binding interfaces of WNT and Frizzled unlikely.

The role of the LRP coreceptors in infarct healing has been studied more extensively. Induction of MI in mice deficient in LRP5 resulted in an increase in infarct size (Borrell-Pages et al., 2016) but no change in infarct area or cardiac function, as observed when LRP5 was specifically deleted in CMs (Wo et al., 2016). In several studies, the effect of DKK proteins, endogenous antagonists of LRP proteins, on infarct healing was addressed. Injection of DKK1 in the border zone of the infarct area in mice did not change infarct size or function (Wo et al., 2016). In contrast, DKK2 injection reduced the size of the infarct and improved cardiac function in rats at 1 week post-MI, which was attributed by the authors to a positive effect on angiogenesis (Min et al., 2011). Beneficial effects on infarct healing were observed in mice overexpressing DKK3 in a CM-specific manner, though the authors proposed a cardioprotective mechanism via apoptosis signal-regulating kinase 1-c-Jun $N$-terminal kinase (ASK1-JNK) and p38 rather than WNT signaling (Bao et al., 2015). Though the results are not univocal, the majority of studies shows that interruption of LRP5/6 signaling has beneficial effects on infarct healing.

sFRPs. Interventions at the level of the sFRPs has been studied quite extensively by diverse research groups. Barandon et al. (2003) studied the effect of overexpression of sFRP1 on infarct healing in the mouse. Mice overexpressing the sFRP1 analog FrzA under the control of the cytomegalovirus promoter showed smaller infarcts after either left anterior descending coronary artery occlusion or cryoinjury. This was accompanied by improved cardiac function at 15 days post-MI, less apoptosis and leukocyte infiltration in the first week after MI, and a 3-fold increase in capillary density in the scar area (Barandon et al., 2003). In a follow-up study, it was shown that the infiltration of neutrophils in the infarct area could be reduced when sFRP1-overexpressing bone marrow cells were transplanted into wild-type recipients, thereby switching the balance toward anti-inflammatory cytokine production (Barandon et al., 2011).

Regarding the role of sFRP2 in infarct healing, contradictory results have been published. sFRP2 was shown to be a key paracrine factor produced by stem cells injected around the infarct area, resulting in improved myocardial survival and repair after MI (Mirotsou et al., 2007). Overexpression of sFRP2 in mesenchymal stem cells injected around the infarct area further enhanced the beneficial effect on infarct healing and cardiac function in infarcted mice (Alfaro et al., 2008). When injected directly into the border zone of the infarcted rat heart, sFRP2 reduced left ventricular fibrosis, prevented anterior wall thinning, and improved cardiac function via inhibition of bone morphogenetic protein/Tolloid-like metalloproteinase (He et al., 2010). In contrast, fibrosis was found to 
be markedly reduced in sFRP2-null mice subjected to MI (Kobayashi et al., 2009). Moreover, sFRP2 induced marked proliferation of cardiac fibroblasts (Lin et al., 2016), and in the failing hamster heart, this profibrotic response could be counteracted by treatment with a sFRP2 antibody, which reduced myocardial fibrosis and improved function (Mastri et al., 2014). At present, it is unclear how these inconsistent results can be explained.

Interventions in Destruction Complex. The $\beta$-catenin destruction complex consists of multiple partners, of which GSK3- $\beta$ and CK1 are involved in the phosphorylation of $\beta$-catenin, the first step in the degradation of this second messenger. The potential role of GSK3- $\beta$ in cardiac regeneration has been investigated both by genetic and pharmacological interventions. Because the global GSK3- $\beta$ knockout is lethal, Woulfe et al. (2010) tested the effect of a tamoxifeninducible CM-specific GSK3- $\beta$ knockout on the wound healing after MI. Administration of tamoxifen from 3 to 8 days post-MI did not reduce infarct size but improved cardiac function at 8 weeks post-MI and more than doubled the BrdU incorporation in CMs in the border zone (Woulfe et al., 2010). Administration of the GSK3- $\beta$-inhibitor BIO to infarcted rats for 2 weeks resulted in reduced ventricular fibrosis and improved cardiac function, but changes in infarct size or stimulation of CM proliferation were not reported in this study (Kim et al., 2016). Recently, Badimon et al. (2019) reported a small but significant decrease in infarct size in mice treated with the GSK3 inhibitor SB415286; however, this effect was only observed in an ischemia-reperfusion model and not after permanent coronary ligation (Badimon et al., 2019). In this context, it has to be noted that GSK3- $\beta$-signaling in the heart is under the control of multiple other signaling pathways, as recently reviewed by Singh et al. (2019) and illustrated in Fig. 2.

The effect of inhibition of CK1 with the FDA-approved antihelminthic compound pyrvinium on infarct healing was addressed in two studies. Saraswati et al. (2010) reported that a single intramyocardial injection of this compound resulted in a decreased expansion of the diastolic diameter of the left ventricle, despite similar infarct size and no change in fractional shortening. Moreover, increased numbers of Ki67 myocytes were observed in the border zone and remote areas. However, because intracardiac pyrvinium administration was found to be lethal in more than $50 \%$ of the treated mice in this study, alternative administration routes had to be explored for this compound. Intragastric administration of pyrvinium in a mouse model of MI from days 1 to 14 post-MI resulted in less dilatation, fewer myofibroblasts, and less fibrosis in the infarct area. Furthermore, this intervention resulted in improved cardiac function compared with control treatment. Inhibition of WNT signaling by administering the compound SEN195 (a stabilizer of axin, the main scaffold protein in the destruction complex) for 4 weeks reduced the dilatation post-MI and improved ejection fraction in the infarcted rat heart when compared with vehicle treatment with concomitant inhibition of $\mathrm{WNT} / \beta$-catenin signaling in the border zone of the infarct (Matteucci et al., 2016). Similar results were obtained in the zebrafish model of apical resection, in which endocardial Notch inhibition resulted in the release of the WNT inhibitors WNT inhibitory factor 1 (Wif1) and palmitoleoyl-protein carboxylesterase $1 \mathrm{~b}$ (Notum1b). In this study, application of the tankyrase inhibitor IWR-1 (an axin2 stabilizer) stimulated CM proliferation and cardiac regeneration. On the contrary, activation of $\mathrm{WNT} / \beta$-catenin signaling with BIO inhibited CM proliferation and induced scarring (Zhao et al., 2019). Though in most of the studies in which the destruction complex was targeted CM proliferation was not specifically investigated, the reduction in infarct size and improved function observed in most of these studies suggests that this intervention is beneficial for cardiac regeneration.

Nuclear $\beta$-Catenin Signaling. Direct interventions at the level of nuclear $\beta$-catenin have yielded mixed results on infarct healing. Injection of an adenovirus expressing a constitutively active form of $\beta$-catenin in the border zone of the rat infarct was reported to reduce infarct size by cell cycle activation in both CMs and fibroblasts. In the CMs, the cell cycle was not completed, giving rise to binucleation and

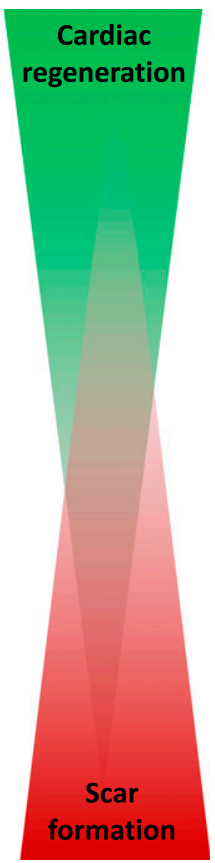

Fig. 2. Overview of the main signaling pathways involved in cardiomyocyte proliferation. Most of the pathways activate the expression of genes involved in the initiation of the cell cycle (G1/S phase), whereas p38MAPK is more associated with the regulation of the expression of genes associated with the late phase of the cell cycle (G2/M phase) (Hashmi and Ahmad, 2019). Extensive crosstalk has been reported between the different signaling pathways, as indicated by the green and red lines, as described in the text. Please note that most of the signaling pathways appear to be connected, either directly or indirectly, to the PI3K/AKT/GSK3- $\beta$ axis. For an explanation of the abbreviations, please refer to the list of nonstandard abbreviations provided with this manuscript. 
hypertrophy. The attenuation of CM apoptosis may have contributed to the beneficial effect on infarct healing (Hahn et al., 2006), though a similar antiapoptotic effect was observed after CM-specific deletion of $\beta$-catenin (Wo et al., 2016). CM-specific deletion of $\beta$-catenin was also reported to be beneficial by improving left ventricular function and CM survival, whereas stabilization had the opposite effect. In this study, a layer of small cells expressing cardiac troponin-T and other cardiac lineage markers was observed at the subepicardial and subendocardial borders of the infarct, which is suggestive for CM proliferation (Zelarayán et al., 2008). A similar observation of cells expressing CM markers at the epicardial side was reported by treating female rats with ICG-001, a compound blocking the binding of $\beta$-catenin to the transcription complex (Sasaki et al., 2013). Recently, targeting WNT/ $\beta$-catenin at the level of the transcription complex was also demonstrated to increase the newly formed CMs and reduce scarring in the zebrafish model of apical amputation (Xie et al., 2019). Taken together, the majority of studies now shows that targeting WNT/ $\beta$-catenin at the level of the transcription complex by either a genetic or a pharmacological intervention induces a proliferative response in cells showing expression of CM markers located at the epicardial and endocardial borders of the infarct.

Discrepancy between In Vitro and In Vivo Results Regarding the Modulation of WNT Signaling. Overseeing the many studies published to date regarding modulation of WNT/ $\beta$-catenin signaling to induce $\mathrm{CM}$ proliferation reveals a rather striking dichotomy: In most of the in vitro studies as well as the in vivo studies wherein CMs are specifically targeted (e.g., by using a CM-specific promotor to drive a transgenic or knockout construct), activation of WNT signaling stimulates the cell cycle of CMs and leads to their proliferation. In contrast, most of the in vivo studies in which WNT signaling is targeted with pharmacological tools delivered either systemically or by local injection showed that inhibition of the pathway results in smaller infarcts and improved cardiac function. An increased proliferation of resident CMs in the border of the infarct area has also been reported in some of these studies. How can this apparent discrepancy be explained? Though this synopsis is generalized and there are certainly exceptions, it may imply that activation of WNT signaling-and more particular $\beta$-catenin-mediated WNT signaling-in CMs is sufficient to induce their proliferation. However, this mechanism might be relatively unimportant in inducing $\mathrm{CM}$ proliferation and cardiac regeneration after $\mathrm{MI}$ in an in vivo setting. As indicated above, infarct healing is a complex interplay between inflammatory cells, vascular endothelial cells, and (myo)fibroblasts and the epicardium and endocardium. Many of the mechanisms involved in the wound-healing response (inflammation, angiogenesis, fibrosis, reinnervation, etc.) have been shown to respond to interventions in WNT signaling as well, as reviewed elsewhere (Dawson et al., 2013; Foulquier et al., 2018). It is quite conceivable that in the plethora of signaling taking place in the healing infarct, inhibition of WNT signaling may tip the balance toward conditions in which other pathways become active to stimulate CM proliferation. Moreover, activated WNT/ $\beta$-catenin signaling in $\mathrm{CMs}$ is associated with a hypertrophic phenotype in vivo characterized by polyploidy/multinucleation and extensively developed contractile apparatus (Haybar et al., 2019). This phenotype could in fact hamper the completion of the cell cycle with cytokinesis, as discussed before. From a therapeutic point of view, a reduction in infarct size combined with CM proliferation and a better-preserved pump function is essential to prevent heart failure development after MI. Because this is what pharmacological inhibition of WNT signaling in in vivo MI models appears to offer, we urgently need to unravel the underlying mechanisms responsible for this beneficial effect.

Follistatin-Like 1. The epicardium is increasingly recognized as an essential structure in infarct healing, because it can serve as a source for secreted factors and cells that are essential for cardiac repair (Cao and Poss, 2018). Wei et al. (2015) tested the delivery of epicardial cell-derived conditioned medium to the infarcted mouse and swine hearts using a collagen patch. They observed a robust decrease in infarct size and preserved pump function, combined with the induction of CM proliferation in the border zone of the infarct. Systematic analysis of the proproliferative factors present in the conditioned medium resulted in the identification of FSTL-1 (Wei et al., 2015). Infusion or adenovirusmediated overexpression of FSTL-1 was already reported previously to have cardioprotective effects after MI (Oshima et al., 2008; Ogura et al., 2012). The post-translational glycosylation of FSTL-1 at position 180 appears to be critical for its effect, because unglycosylated FSTL-1 produced by the epicardium can induce CM proliferation and cardiac regeneration, whereas the glycosylated variant produced by the myocardium has cardioprotective and antiapoptotic effects (Magadum et al., 2018). A reduced infarct size combined with an improved cardiac function was recently reported upon injection of FSTL-1-overexpressing mesenchymal stem cells around the infarct area, though no information was provided on the glycosylation status of the overexpressed FSTL-1 (Shen et al., 2019).

Growth Hormone/Insulin-Like Growth Factor. Growth hormone $(\mathrm{GH})$ and insulin-like growth factor (IGF)-1 are hormones involved in regulation of the normal growth of multiple organs, including the heart. Several lines of evidence indicate that the GH-IGF-1 axis can induce reactivation of the cell cycle in adult CMs. Administration of $\mathrm{GH}$ to female Wistar rats for 8 weeks increased the number of CMs by $33 \%$ and increased the IGF-1 content more than 7-fold (Brüel et al., 2007). The importance of IGF signaling in this context was demonstrated by studying zebrafish with a dominant negative form of the IGF-1 receptor. This interruption in IGF signaling negatively affected CM proliferation during heart development but also during the regeneration after apical resection (Huang et al., 2013). A reduced infarct size and improved cardiac function could be demonstrated in rats when GH embedded in alginate hydrogel was injected in the border zone of the infarcted rat heart (Daskalopoulos et al., 2015). Interestingly, the combined local administration of IGF-1 with the GSK3- $\beta$ inhibitor BIO (please refer to the paragraph on WNT Signaling for details) showed improved cardiac function by promoting revascularization and CM proliferation around the infarct area (Fang et al., 2015). These results show that activation of the GH/IGF-1 axis promotes cardiac regeneration after $\mathrm{MI}$.

Hippo. The Hippo signal transduction pathway plays an essential role in the control of organ size during development. The pathway was originally identified in Drosophila but turned out to be functionally conserved over multiple 
species, including mammals. The pathway makes use of the transcriptional coactivators YAP and TAZ. These coactivators can migrate to the nucleus where they can associate with transcription factors from the transcriptional enhanced associate domain family and promote the transcription of proliferation-stimulating genes. Upon activation of the pathway, a cluster of kinases, including large tumor suppressor (Lats) 1/2, Mst1/2, and Salvador family WW domain containing protein 1 (Sav1), phosphorylate YAP and TAZ, resulting in their ubiquitination and destruction. Therefore, activation of Hippo signaling results in inhibition of the actions of YAP and TAZ on gene transcription and a subsequent attenuation of cell proliferation. Many proteins have been identified to regulate the activity of the Hippo pathway, but the precise mechanism of activation of the signaling pathway is unclear (Zhao et al., 2010).

Further research on Hippo/YAP/TAZ signaling has revealed its importance in cancer development and tissue regeneration in adult organisms (Wang et al., 2018). Inactivation of Hippo pathway components resulted in enlarged hearts with increased CM proliferation not only in mouse embryos (Heallen et al., 2011) but also in adult mice (Heallen et al., 2013). CMspecific deletion of YAP resulted in progressive dilation and heart failure in adult mice and shifted the regenerative response upon cardiac injury toward fibrosis in newborn mice, whereas overexpression of a constitutively active form of YAP had a proregenerative effect (Xin et al., 2013). Genome-wide identification of YAP-bound loci identified phosphatidylinositol4,5-bisphosphate 3-kinase catalytic subunit beta (Pik3cb), a catalytic subunit of phosphoinositide 3-kinase (PI3K), as a YAP effector molecule, linking Hippo signaling to the PI3K/ protein kinase $\mathrm{B}$ (Akt) pathway to regulate CM proliferation and survival (Lin et al., 2014). Inhibition of Hippo signaling by conditionally deleting the pathway component Salvador at 3 weeks post-MI followed by a 6 -week follow-up resulted in less fibrosis, a larger CM area, and an improved function compared with wild-type controls (Leach et al., 2017). Taken together, these studies support an inhibitory role for Hippo signaling on CM proliferation and cardiac regeneration in newborn and adult mice (Wang et al., 2018). Recently, a novel drug named TT-10 was described that enhances YAP-TAZ activity, resulting in increased proliferation of murine CMs in vitro (Ito et al., 2019). Intraperitoneal injection of TT-10 in infarcted mice reduced infarct size, improved cardiac function, and increased the numbers of phosphorylated histone-3and Aurora B-positive CMs in the border zone (Hara et al., 2018). These results provide a perspective for pharmacological rather than genetic intervention in Hippo signaling to stimulate CM proliferation in injured hearts.

Neuregulin-1. Neuregulin-1 (NRG-1) is a member of the neuregulin growth factor family and is the isoform most present in the heart, where the tyrosine kinase receptors ErbB4 and-to a lesser extent-ErbB3 serve as its receptors (Rupert and Coulombe, 2015). Upon binding, ErbB receptors can form a heterodimer with ErbB2 and activate cardioprotective signaling pathways (Vermeulen et al., 2016). The importance of the ErbB2 protein in cardiac physiology was highlighted in studies in which cardiotoxicity was reported in patients with breast cancer treated with trastuzumab, a recombinant monoclonal antibody directed against ErbB2. These adverse cardiac events were particularly apparent in patients who received trastuzumab in combination with other chemotherapeutics, such as anthracyclins (Slamon et al., 2001), suggesting an impaired capacity of the heart to repair damage.

NRG-1/ErbB signaling in cardiac regeneration and CM proliferation has been studied extensively in zebrafish. Upon cardiac injury, NRG-1 expression peaked to more than 10 -fold of the control values at 7 days after injury; the expression appeared to be localized in the outer layers of the ventricle. Pharmacological inhibition of ErbB receptors with the inhibitor AG1478 decreased CM proliferation by $~ 50 \%$. On the other hand, overexpression of NRG-1 in uninjured hearts induced CM dedifferentiation and subsequent proliferation, resulting in cardiomegaly. These findings support a stimulating role for NRG-1 on CM proliferation in zebrafish. Moreover, NRG-1 overexpression regulated recruitment of non-CMs and blood vessel formation in the area of injury imperative for successful cardiac regeneration (Gemberling et al., 2015). Evidence for a similar role of NRG-1/ErbB signaling in mammalian CM proliferation was collected by studying ErbB2 expression in neonatal mouse hearts. A marked reduction in ErbB2 expression in the first week after birth was paralleled by a loss of CM proliferation. Moreover, conditional ErbB2 ablation in the neonatal mouse heart attenuated cell cycle activation and CM proliferation in the first week after birth (D'Uva et al., 2015; Ma et al., 2016).

Activation of NRG/ErbB signaling in mammalian models of cardiac remodeling resulted in an improved left ventricular structure and function with a concomitant reduction in CM apoptosis, increased angiogenesis, and reduced cardiac fibrosis (Vermeulen et al., 2016). These positive results formed the basis for several clinical trials. Administration of a 61-aa peptide covering the epidermal growth factor domain of human NRG-1 to patients with human heart failure resulted in reduced end-systolic and end-diastolic volumes and improved acute and long-term hemodynamic effects, though a clear dose-response relationship was lacking (Gao et al., 2010; Jabbour et al., 2011). A sustained and dose-dependent improvement of the left ventricular ejection fraction was observed in a study by Lenihan et al. (2016), in which ascending doses of the full-length recombinant NRG-1- $\beta 3$, also known as cimaglerin alfa, was administered to patients with heart failure. However, it has to be noted that-in contrast to the animal studies-no results have been published from studies in which NRG1 treatment is tested in patients with acute MI.

Because of its interaction with different members of the ErbB family, NRG-1 can activate multiple signaling pathways. As mentioned above, CMs contain ErbB2, ErbB3, and ErbB4 receptors, the latter two being able to interact with NRG-1. For ErbB signaling, dimerization is required; this can either be homo-dimerization or hetero-dimerization of, for example, ErbB2 and ErbB4. Heterodimers of ErbB2 and ErbB3/4 can activate extracellular receptor kinase (ERK) signaling, whereas ErbB4 homodimers can activate the Akt pathway. In both cases, this stimulates CM growth, proliferation, and survival. Using bivalent NRG-1, the formation of ErbB4 homodimers could be promoted, and this was sufficient for the cardioprotective effect. Experiments performed by D'Uva et al. (2015) suggest that CM dedifferentiation and proliferation were ERK-dependent, whereas CM hypertrophy and survival could be promoted by both Akt- and ERKactivation. 
Notch. Notch signaling is a highly conserved pathway involved in cell-cell communication during development and in adult life. In mammals, the pathway consists of the Notch family of receptors (Notch 1-4), single-pass transmembrane proteins with a large extracellular domain. The ligands for this receptor family are also single-pass transmembrane proteins; in mammals, they are named Jagged-1 and -2 and Delta-1, -3 , and -4. Activation of the pathway requires close contact of two neighboring cells, one expressing the ligand and the other the receptor. Upon this interaction, the Notch protein is cleaved by TNF $\alpha$ converting enzyme (extracellularly) and $\gamma$-secretase (intracellularly), and the intracellular domain of the Notch receptor travels to the nucleus where it can interact with the transcription repressor recombination signal binding protein for immunoglobulin $\kappa \mathrm{J}$ region to activate transcription of specific genes, such as mastermind-like (Luxan et al., 2016).

Manipulation of Notch signaling during development can give rise to a plethora of cardiovascular phenotypes; for an overview, we refer to a review article by Gude and Sussman (2012). Notch signaling was reported to be inactive in adult mouse hearts, but activation of Notch signaling in the border zone of the infarct area reduced infarct size, improved cardiac function, and activated proliferative signaling in mice (Gude et al., 2008). Interestingly, the cardiac regeneration observed in zebrafish was also shown to be dependent on Notch signaling, because inhibition of the pathway resulted in scar formation rather than cardiac regeneration upon amputation of the ventricular apex (Zhao et al., 2014). In a follow-up study from the same research group, it was shown that Notch receptors are expressed in epicardium and endocardium rather than in myocardium and that Notch-mediated CM proliferation was dependent on the transcription of the WNT inhibitors Wif1 and Notum $1 b$ in endocardial cells (Zhao et al., 2019). These results support the importance of crosstalk between different cell types in the infarcted heart.

\section{Crosstalk between Signaling Pathways to Promote Cardiomyocyte Proliferation}

In a recent study, Mohamed et al. (2018) reported that overexpression of the cell cycle proteins cyclin B1 and D1, together with cyclin-dependent kinase- 1 and -4 , was sufficient to induce proliferation in $15 \%-20 \%$ of postmitotic CMs obtained from different species. This study supports the idea that the variety of signaling pathways, which was discussed in the previous paragraphs of this review, eventually have to converge into a limited number of nodal points controlling the cell cycle in CMs, as recently reviewed by Hashmi and Ahmad (2019). In Fig. 2, a simplified overview of the main signaling pathways is presented; most of the signaling pathways appear to interact with the PI3K/AKT/ GSK3- $\beta$ axis. In some studies, this crosstalk between the different signaling pathways was specifically addressed. The CM proliferation, observed in neonatal mice in which Hippo signaling was inactivated, resulted in increased nuclear $\beta$-catenin accumulation and could be corrected by deleting a single $\beta$-catenin allele in the $\mathrm{CMs}$ (Heallen et al., 2011). Along similar lines, the activation of endocardial Notch signaling in zebrafish hearts upon injury was shown to induce the release of two inhibitors of WNT signaling: Wif1 and Notum1b. Administration of the WNT inhibitor IWR-1-endo could partially restore CM proliferation in hearts with defective endocardial Notch signaling, illustrating the crosstalk between Notch and WNT/ $\beta$-catenin signaling in the regenerating zebrafish heart (Zhao et al., 2019). From these examples, it becomes apparent that studying signaling pathways in an isolated, one-dimensional fashion is insufficient for the detection of critical nodal points in the control of CM proliferation.

At present, five major signaling pathways appear to be involved in the control of CM proliferation: 1) Hippo/YAP/ TAZ signaling, 2) WNT/ $\beta$-catenin signaling, 3) p38 mitogenactivated protein kinase (MAPK) signaling, 4) PI3K-Akt signaling, and 5) Janus kinase/signal transducer and activator of transcription (Jak/Stat) signaling. These pathways and some points of crosstalk between them are illustrated in Fig. 2, together with the mediators that control the activity of the pathways. Recently, an overview of the effects of these pathways on the different phases of the cell cycle was published by Hashmi and Ahmad (2019). In their model, cyclin $\mathrm{D}$ activity is under the control of Hippo, Wnt/ $\beta$-catenin, and PI3K-Akt signaling, suggesting the involvement of these pathways in the initiation of the cell cycle. On the other hand, cyclins A and B, which stimulate entry into the G2 and mitosis phase, are negatively regulated by p38-MAPK. This could imply that interventions aiming at inhibition of the pathway promote the completion of the cell cycle by cytokinesis rather than by binucleation or polyploidy.

The molecular mechanisms controlling the processes of degradation of the contractile apparatus and cytokinesis, which are both essential for a complete proliferative cycle of a CM yielding two daughter cells, are not as well understood. Oncostatin $\mathrm{M}$ was reported to induce sarcomere disassembly via ERK1/2 activation, whereas IGF-1 can reverse this process (Szibor et al., 2014; Yuan and Braun, 2017). Interestingly, a $\beta$-catenin-independent WNT signaling pathway involving WNT5a was reported to stimulate cytokinesis by stabilizing microtubules at the midbody. Inactivation of WNT5a signaling was shown to induce multinucleation (Fumoto et al., 2012), a phenomenon that is very common in CM.

\section{Conclusions}

Extensive research efforts in the last decade have taught us that proliferation of adult CMs in mammalian hearts actually exists and can be manipulated, as illustrated in Fig. 1. This opens up potential new avenues for cardiac regeneration upon injury of the heart. Further exploration of the signaling pathways involved in the control of this exciting process are urgently needed to shift the therapy of heart failure from treating the symptoms ("care") to an actual repair of the problem ("cure"). However, from the overview of the literature presented in this review it is clear that we have just scratched the surface of the complex signaling involved in the control of CM proliferation. Before rushing toward clinical trials, it is mandatory to expand our knowledge on the molecular control of CM proliferation. This is of particular importance in the context of the infarcted heart, wherein the relevance of crosstalk between CMs and other cells and structures has become apparent. To achieve this, the following aspects should be addressed:

1. It is quite obvious that the multiple signaling pathways implicated in CM proliferation have to converge 
at critical nodal points to activate the different stages of CM proliferation in the correct order. In most of the studies cited in this review, however, signaling pathways are approached in a rather one-dimensional fashion. Now that the evidence is mounting for extensive crosstalk between the different pathways, we have to move toward experimental approaches in which the signaling is studied in a more integrated fashion.

2. Most of the in vitro studies included in this review make use of cultures of CMs typically grown in a twodimensional layer on the rigid surface of a cell culture plate. Particularly for ventricular CMs, this is a very distant reflection of their normal habitat, where they are embedded in extracellular matrix in close contact with fibroblasts and capillaries and rhythmically paced. Moreover, either neonatal rat ventricular CMs or CMs derived from stem cells may not sufficiently reflect the characteristics of an adult CM stressed by low oxygen supply, as will be the case in the border zone of the infarct. This problem is nicely illustrated by the conflicting results regarding the manipulation of WNT signaling obtained in vitro (stimulation induces cultured CM proliferation) versus in vivo (inhibition of WNT signaling promotes CM proliferation in the border zone of the infarct and cardiac regeneration). As discussed in the chapter on WNT signaling, interaction of the CMs with the many cell types implicated in infarct healing (inflammatory cells, vascular endothelial cells, fibroblasts, epicardial/endocardial epithelium, nerve cells) apparently gives rise to an environment where this pathway is activated too strongly for CMs to complete the cell cycle and may in fact progress to a hypertrophic phenotype. Though it will be challenging from an experimental point of view, these discrepancies need to be solved to acquire sufficient understanding of the underlying mechanisms to move toward clinical application of the findings.

3. In most studies, CM proliferation is approached with a strong focus on the induction of the cell cycle per se. This appears to be an oversimplification, because complete CM proliferation including cytokinesis will require extensive degradation of the sarcomeric structure (Szibor et al., 2014). At present, little is known about this process, other than that stimuli, such as oncostatin $\mathrm{M}$, can induce the CM dedifferentiation required for cytokinesis (Pöling et al., 2012). Interestingly, dedifferentiation can also be observed in CMs in the border zone of the infarct area. This process may resemble CM hibernation, a term defined several decades ago describing changes in contractile machinery and cell metabolism in CMs under stress (Szibor et al., 2014). Insufficient dedifferentiation may actually impair cytokinesis (Jopling et al., 2010), driving the CM toward polyploidy, multinucleation, and the hypertrophic phenotype that is frequently observed in injured hearts. On the other hand, redifferentiation of the daughter cells will also be required after successful division of a CM (Szibor et al., 2014). This has to be accompanied by appropriate electromechanical coupling to the cellular environment (Ali et al., 2014) to make the daughter cells contribute efficiently to the cardiac contraction and avoid arrhythmias. This may mean that interventions have to be carefully timed during the wound healing following MI to address the different phases of the CM proliferation with the appropriate instruments.

\section{Authorship Contributions}

Participated in research design: Blankesteijn.

Performed data analysis: Blankesteijn.

Wrote or contributed to the writing of the manuscript: Blankesteijn.

\section{References}

Aisagbonhi O, Rai M, Ryzhov S, Atria N, Feoktistov I, and Hatzopoulos AK (2011) Experimental myocardial infarction triggers canonical Wnt signaling and endothelial-to-mesenchymal transition. Dis Model Mech 4:469-483.

Alfaro MP, Pagni M, Vincent A, Atkinson J, Hill MF, Cates J, Davidson JM, Rottman J, Lee E, and Young PP (2008) The Wnt modulator sFRP2 enhances mesenchymal stem cell engraftment, granulation tissue formation and myocardial repair. Proc Natl Acad Sci USA 105:18366-18371.

Ali SR, Hippenmeyer S, Saadat LV, Luo L, Weissman IL, and Ardehali R (2014) Existing cardiomyocytes generate cardiomyocytes at a low rate after birth in mice. Proc Natl Acad Sci USA 111:8850-8855.

Alvarez R Jr, Wang BJ, Quijada PJ, Avitabile D, Ho T, Shaitrit M, Chavarria M, Firouzi F, Ebeid D, Monsanto MM, et al. (2019) Cardiomyocyte cell cycle dynamics and proliferation revealed through cardiac-specific transgenesis of fluorescent ubiquitinated cell cycle indicator (FUCCI). $J$ Mol Cell Cardiol 127:154-164.

Badimon L, Casaní L, Camino-Lopez S, Juan-Babot O, and Borrell-Pages M (2019) GSK3 $\beta$ inhibition and canonical Wnt signaling in mice hearts after myocardial ischemic damage. PLoS One 14:e0218098.

Bao MW, Cai Z, Zhang XJ, Li L, Liu X, Wan N, Hu G, Wan F, Zhang R, Zhu X, et al. (2015) Dickkopf-3 protects against cardiac dysfunction and ventricular remodelling following myocardial infarction. Basic Res Cardiol 110:25.

Barandon L, Casassus F, Leroux L, Moreau C, Allières C, Lamazière JM, Dufourcq P, Couffinhal T, and Duplàa C (2011) Secreted frizzled-related protein-1 improves postinfarction scar formation through a modulation of inflammatory response. Arterioscler Thromb Vasc Biol 31:e80-e87.

Barandon L, Couffinhal T, Ezan J, Dufourcq P, Costet P, Alzieu P, Leroux L, Moreau C, Dare D, and Duplàa C (2003) Reduction of infarct size and prevention of cardiac rupture in transgenic mice overexpressing FrzA. Circulation 108:2282-2289.

Bastakoty D and Young PP (2016) Wnt/ß-catenin pathway in tissue injury: roles in pathology and therapeutic opportunities for regeneration. FASEB $J$ 30:3271-3284.

Bergmann O (2019) Clearing up the mist: cardiomyocyte renewal in human hearts. Eur Heart J 40:1037-1038.

Bergmann O, Bhardwaj RD, Bernard S, Zdunek S, Barnabé-Heider F, Walsh S, Zupicich J, Alkass K, Buchholz BA, Druid H, et al. (2009) Evidence for cardiomyocyte renewal in humans. Science 324:98-102.

Blankesteijn WM, Essers-Janssen YP, Verluyten MJ, Daemen MJ, and Smits JF (1997) A homologue of Drosophila tissue polarity gene frizzled is expressed in migrating myofibroblasts in the infarcted rat heart. Nat Med 3:541-544.

Borrell-Pages M, Vilahur G, Romero JC, Casaní L, Bejar MT, and Badimon L (2016) LRP5/canonical Wnt signalling and healing of ischemic myocardium. Basic Res Cardiol 111:67.

Braunwald E (2018) Cell-based therapy in cardiac regeneration: an overview. Circ Res 123:132-137.

Brüel A, Christoffersen TE, and Nyengaard JR (2007) Growth hormone increases the proliferation of existing cardiac myocytes and the total number of cardiac myocytes in the rat heart. Cardiovasc Res 76:400-408.

Buikema JW, Mady AS, Mittal NV, Atmanli A, Caron L, Doevendans PA, Sluijter JP, and Domian IJ (2013) Wnt/ $\beta$-catenin signaling directs the regional expansion of first and second heart field-derived ventricular cardiomyocytes. Development 140: $4165-4176$.

Cao J and Poss KD (2018) The epicardium as a hub for heart regeneration. Nat Rev Cardiol 15:631-647.

Cleutjens JP, Blankesteijn WM, Daemen MJ, and Smits JF (1999) The infarcted myocardium: simply dead tissue, or a lively target for therapeutic interventions. Cardiovasc Res 44:232-241.

Cruciat CM and Niehrs C (2013) Secreted and transmembrane wnt inhibitors and activators. Cold Spring Harb Perspect Biol 5:a015081.

Daskalopoulos EP, Vilaeti AD, Barka E, Mantzouratou P, Kouroupis D, Kontonika M, Tourmousoglou C, Papalois A, Pantos C, Blankesteijn WM, et al. (2015) Attenuation of post-infarction remodeling in rats by sustained myocardial growth hormone administration. Growth Factors 33:250-258.

Dawson K, Aflaki M, and Nattel S (2013) Role of the Wnt-Frizzled system in cardiac pathophysiology: a rapidly developing, poorly understood area with enormous potential. J Physiol 591:1409-1432.

D'Uva G, Aharonov A, Lauriola M, Kain D, Yahalom-Ronen Y, Carvalho S, Weisinger $\mathrm{K}$, Bassat E, Rajchman D, Yifa O, et al. (2015) ERBB2 triggers mammalian heart regeneration by promoting cardiomyocyte dedifferentiation and proliferation. Nat Cell Biol 17:627-638.

Eschenhagen T, Bolli R, Braun T, Field LJ, Fleischmann BK, Frisén J, Giacca M, Hare JM, Houser S, Lee RT, et al. (2017) Cardiomyocyte regeneration: a consensus statement. Circulation 136:680-686.

Fan Y, Ho BX, Pang JKS, Pek NMQ, Hor JH, Ng SY, and Soh BS (2018) Wnt/ $\beta$-catenin-mediated signaling re-activates proliferation of matured cardiomyocytes. Stem Cell Res Ther 9:338.

Fang R, Qiao S, Liu Y, Meng Q, Chen X, Song B, Hou X, and Tian W (2015) Sustained co-delivery of BIO and IGF-1 by a novel hybrid hydrogel system to stimulate 
endogenous cardiac repair in myocardial infarcted rat hearts. Int $J$ Nanomedicine 10:4691-4703.

Foglia MJ and Poss KD (2016) Building and re-building the heart by cardiomyocyte proliferation. Development 143:729-740.

Foulquier S, Daskalopoulos EP, Lluri G, Hermans KCM, Deb A, and Blankesteijn WM (2018) WNT signaling in cardiac and vascular disease. Pharmacol Rev 70:68-141.

Fumoto K, Kikuchi K, Gon H, and Kikuchi A (2012) Wnt5a signaling controls cytokinesis by correctly positioning ESCRT-III at the midbody. J Cell Sci 125: $4822-4832$

Gao R, Zhang J, Cheng L, Wu X, Dong W, Yang X, Li T, Liu X, Xu Y, Li X, et al. (2010) A Phase II, randomized, double-blind, multicenter, based on standard therapy, placebocontrolled study of the efficacy and safety of recombinant human neuregulin-1 in patients with chronic heart failure. J Am Coll Cardiol 55:1907-1914.

Gemberling M, Karra R, Dickson AL, and Poss KD (2015) Nrg1 is an injury-induced cardiomyocyte mitogen for the endogenous heart regeneration program in zebrafish. eLife 4:1-17.

González-Rosa JM, Martín V, Peralta M, Torres M, and Mercader N (2011) Extensive scar formation and regression during heart regeneration after cryoinjury in zebrafish. Development 138:1663-1674.

Gude N and Sussman M (2012) Notch signaling and cardiac repair. J Mol Cell Cardiol 52:1226-1232.

Gude NA, Emmanuel G, Wu W, Cottage CT, Fischer K, Quijada P, Muraski JA, Alvarez R, Rubio M, Schaefer E, et al. (2008) Activation of Notch-mediated protective signaling in the myocardium. Circ Res 102:1025-1035.

Günthel M, Barnett P, and Christoffels VM (2018) Development, proliferation, and growth of the mammalian heart. Mol Ther 26:1599-1609.

Hahn JY, Cho HJ, Bae JW, Yuk HS, Kim KI, Park KW, Koo BK, Chae IH, Shin CS, $\mathrm{Oh} \mathrm{BH}$, et al. (2006) Beta-catenin overexpression reduces myocardial infarct size through differential effects on cardiomyocytes and cardiac fibroblasts. $J$ Biol Chem 281:30979-30989.

Hara H, Takeda N, Kondo M, Kubota M, Saito T, Maruyama J, Fujiwara T, Maemura S, Ito M, Naito AT, et al. (2018) Discovery of a small molecule to increase cardiomyocytes and protect the heart after ischemic injury. JACC Basic Transl Sci 3:639-653.

Harterink M and Korswagen HC (2012) Dissecting the Wnt secretion pathway: key questions on the modification and intracellular trafficking of Wnt proteins. Acta Physiol (Oxf) 204:8-16.

Hashmi S and Ahmad HR (2019) Molecular switch model for cardiomyocyte proliferation. Cell Regen (Lond) 8:12-20.

Haybar H, Khodadi E, and Shahrabi S (2019) Wnt/ß-catenin in ischemic myocardium: interactions and signaling pathways as a therapeutic target. Heart Fail Rev 24:411-419.

He W, Zhang L, Ni A, Zhang Z, Mirotsou M, Mao L, Pratt RE, and Dzau VJ (2010) Exogenously administered secreted frizzled related protein 2 (Sfrp2) reduces fibrosis and improves cardiac function in a rat model of myocardial infarction. Proc Natl Acad Sci USA 107:21110-21115.

Heallen T, Morikawa Y, Leach J, Tao G, Willerson JT, Johnson RL, and Martin JF (2013) Hippo signaling impedes adult heart regeneration. Development 140: $4683-4690$.

Heallen T, Zhang M, Wang J, Bonilla-Claudio M, Klysik E, Johnson RL, and Martin JF (2011) Hippo pathway inhibits Wnt signaling to restrain cardiomyocyte proliferation and heart size. Science 332:458-461.

Hermans KC, Daskalopoulos EP, and Blankesteijn WM (2016) The Janus face of myofibroblasts in the remodeling heart. J Mol Cell Cardiol 91:35-41.

Hesse M, Doengi M, Becker A, Kimura K, Voeltz N, Stein V, and Fleischmann BK (2018) Midbody positioning and distance between daughter nuclei enable unequivocal identification of cardiomyocyte cell division in mice. Circ Res 123: 1039-1052.

Huang Y, Harrison MR, Osorio A, Kim J, Baugh A, Duan C, Sucov HM, and Lien CL (2013) Igf signaling is required for cardiomyocyte proliferation during zebrafish heart development and regeneration. PLoS One 8:e67266.

Ito M, Hara H, Takeda N, Naito AT, Nomura S, Kondo M, Hata Y, Uchiyama M, Morita H, and Komuro I (2019) Characterization of a small molecule that promotes cell cycle activation of human induced pluripotent stem cell-derived cardiomyocytes. J Mol Cell Cardiol 128:90-95.

Jabbour A, Hayward CS, Keogh AM, Kotlyar E, McCrohon JA, England JF, Amor R, Liu X, Li XY, Zhou MD, et al. (2011) Parenteral administration of recombinant human neuregulin-1 to patients with stable chronic heart failure produces favourable acute and chronic haemodynamic responses. Eur J Heart Fail 13:83-92. Janda CY, Waghray D, Levin AM, Thomas C, and Garcia KC (2012) Structural basis of Wnt recognition by Frizzled. Science 337:59-64.

Jopling C, Sleep E, Raya M, Martí M, Raya A, and Izpisúa Belmonte JC (2010) Zebrafish heart regeneration occurs by cardiomyocyte dedifferentiation and proliferation. Nature 464:606-609.

Kim YS, Jeong HY, Kim AR, Kim WH, Cho H, Um J, Seo Y, Kang WS, Jin SW, Kim MC, et al. (2016) Natural product derivative BIO promotes recovery after myocardial infarction via unique modulation of the cardiac microenvironment. Sci Rep 6:30726.

Kobayashi K, Luo M, Zhang Y, Wilkes DC, Ge G, Grieskamp T, Yamada C, Liu TC, Huang G, Basson CT, et al. (2009) Secreted Frizzled-related protein 2 is a procollagen $\mathrm{C}$ proteinase enhancer with a role in fibrosis associated with myocardial infarction. Nat Cell Biol 11:46-55.

Laeremans H, Hackeng TM, van Zandvoort MA, Thijssen VL, Janssen BJ, Ottenheijm HC, Smits JF, and Blankesteijn WM (2011) Blocking of frizzled signaling with a homologous peptide fragment of wnt3a/wnt5a reduces infarct expansion and prevents the development of heart failure after myocardial infarction. Circulation 124: $1626-1635$.

Lam NT and Sadek HA (2018) Neonatal heart regeneration. Circulation 138: $412-423$

Leach JP, Heallen T, Zhang M, Rahmani M, Morikawa Y, Hill MC, Segura A, Willerson JT, and Martin JF (2017) Hippo pathway deficiency reverses systolic heart failure after infarction. Nature 550:260-264.
Lenihan DJ, Anderson SA, Lenneman CG, Brittain E, Muldowney JAS III, Mendes L, Zhao PZ, Iaci J, Frohwein S, Zolty R, et al. (2016) A phase I, single ascending

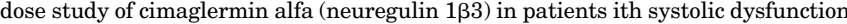
and heart failure. JACC Basic Transl Sci 1:576-586.

Leone M, Musa G, and Engel FB (2018) Cardiomyocyte binucleation is associated with aberrant mitotic microtubule distribution, mislocalization of RhoA and IQGAP3, as well as defective actomyosin ring anchorage and cleavage furrow ingression. Cardiovasc Res 114:1115-1131.

Lin H, Angeli M, Chung KJ, Ejimadu C, Rosa AR, and Lee T (2016) sFRP2 activates Wnt/ $\beta$-catenin signaling in cardiac fibroblasts: differential roles in cell growth energy metabolism, and extracellular matrix remodeling. Am J Physiol Cell Physiol 311:C710-C719.

Lin Z, von Gise A, Zhou P, Gu F, Ma Q, Jiang J, Yau AL, Buck JN, Gouin KA, van Gorp PR, et al. (2014) Cardiac-specific YAP activation improves cardiac function and survival in an experimental murine MI model. Circ Res 115:354-363.

Luxan G, D'Amato G, and de la Pompa JL (2016) Intercellular signaling in cardiac development and disease: the NOTCH pathway, in Etiology and Morphogenesis of Congenital Heart Disease: From Gene Function and Cellular Interaction to Morphology (Nakanishi T, Markwald RR, Baldwin HS, Keller BB, Srivastava D, and Yamagishi H eds) pp 103-114, Springer, Tokyo, Japan.

Ma H, Yin C, Zhang Y, Qian L, and Liu J (2016) ErbB2 is required for cardiomyocyte proliferation in murine neonatal hearts. Gene 592:325-330.

MacDonald BT, Tamai K, and He X (2009) Wnt/beta-catenin signaling: components, mechanisms, and diseases. Dev Cell 17:9-26.

Magadum A, Singh N, Kurian AA, Sharkar MTK, Chepurko E, and Zangi L (2018) Ablation of a single N-glycosylation site in human FSTL 1 induces cardiomyocyte proliferation and cardiac regeneration. Mol Ther Nucleic Acids 13:133-143.

Mastri M, Shah Z, Hsieh K, Wang X, Wooldridge B, Martin S, Suzuki G, and Lee T (2014) Secreted Frizzled-related protein 2 as a target in antifibrotic therapeutic intervention. Am J Physiol Cell Physiol 306:C531-C539.

Matteucci M, Casieri V, Gabisonia K, Aquaro GD, Agostini S, Pollio G, Diamanti D, Rossi M, Travagli M, Porcari V, et al. (2016) Magnetic resonance imaging of infarctinduced canonical wingless/integrated $(\mathrm{Wnt}) / \beta$-catenin/T-cell factor pathway activation, in vivo. Cardiovasc Res 112:645-655.

Min JK, Park H, Choi HJ, Kim Y, Pyun BJ, Agrawal V, Song BW, Jeon J, Maeng YS, Rho SS, et al. (2011) The WNT antagonist Dickkopf2 promotes angiogenesis in rodent and human endothelial cells. J Clin Invest 121:1882-1893.

Mirotsou M, Zhang Z, Deb A, Zhang L, Gnecchi M, Noiseux N, Mu H, Pachori A, and Dzau V (2007) Secreted frizzled related protein 2 (Sfrp2) is the key Aktmesenchymal stem cell-released paracrine factor mediating myocardial survival and repair. Proc Natl Acad Sci USA 104:1643-1648.

Mohamed TMA, Ang YS, Radzinsky E, Zhou P, Huang Y, Elfenbein A, Foley A, Magnitsky S, and Srivastava D (2018) Regulation of cell cycle to stimulate adult cardiomyocyte proliferation and cardiac regeneration. Cell 173 (1):104-116.e12.

Moon J, Zhou H, Zhang LS, Tan W, Liu Y, Zhang S, Morlock LK, Bao X, Palecek SP, Feng JQ, et al. (2017) Blockade to pathological remodeling of infarcted heart tissue using a porcupine antagonist. Proc Natl Acad Sci USA 114:1649-1654.

Morishita Y, Kobayashi K, Klyachko E, Jujo K, Maeda K, Losordo DW, and Murohara T (2016) Wnt11 gene therapy with adeno-associated virus 9 improves recovery from myocardial infarction by modulating the inflammatory response. Sci Rep 6:21705.

Nakada Y, Canseco DC, Thet S, Abdisalaam S, Asaithamby A, Santos CX, Shah AM, Zhang H, Faber JE, Kinter MT, et al. (2017) Hypoxia induces heart regeneration in adult mice. Nature 541:222-227.

Oerlemans MI, Goumans MJ, van Middelaar B, Clevers H, Doevendans PA, and Sluijter JP (2010) Active Wnt signaling in response to cardiac injury. Basic Res Cardiol 105:631-641.

Ogura Y, Ouchi N, Ohashi K, Shibata R, Kataoka Y, Kambara T, Kito T, Maruyama S, Yuasa D, Matsuo K, et al. (2012) Therapeutic impact of follistatin-like 1 on myocardial ischemic injury in preclinical models. Circulation 126:1728-1738.

Oikonomopoulos A, Sereti KI, Conyers F, Bauer M, Liao A, Guan J, Crapps D, Han JK, Dong H, Bayomy AF, et al. (2011) Wnt signaling exerts an antiproliferative effect on adult cardiac progenitor cells through IGFBP3 Circ Res 109:1363-1374.

Oshima Y, Ouchi N, Sato K, Izumiya Y, Pimentel DR, and Walsh K (2008) Follistatinlike 1 is an Akt-regulated cardioprotective factor that is secreted by the heart. Circulation 117:3099-3108.

Ozhan G and Weidinger G (2015) Wnt/ß-catenin signaling in heart regeneration. Cell Regen (Lond) 4:3.

Paik DT, Rai M, Ryzhov S, Sanders LN, Aisagbonhi O, Funke MJ, Feoktistov I, and Hatzopoulos AK (2015) Wnt10b gain-of-function improves cardiac repair by arteriole formation and attenuation of fibrosis. Circ Res 117:804-816.

Palevski D, Levin-Kotler LP, Kain D, Naftali-Shani N, Landa N, Ben-Mordechai T, Konfino T, Holbova R, Molotski N, Rosin-Arbesfeld R, et al. (2017) Loss of macrophage Wnt secretion improves remodeling and function after myocardial infarction in mice. $J$ Am Heart Assoc 6:1-18.

Pöling J, Gajawada P, Lörchner H, Polyakova V, Szibor M, Böttger T, Warnecke $\mathrm{H}$, Kubin T, and Braun T (2012) The Janus face of OSM-mediated cardiomyocyte dedifferentiation during cardiac repair and disease. Cell Cycle 11: 439-445

Ponnusamy M, Li PF, and Wang K (2017) Understanding cardiomyocyte proliferation: an insight into cell cycle activity. Cell Mol Life Sci 74:1019-1034.

Poss KD, Wilson LG, and Keating MT (2002) Heart regeneration in zebrafish. Science 298:2188-2190.

Puente BN, Kimura W, Muralidhar SA, Moon J, Amatruda JF, Phelps KL, Grinsfelder D, Rothermel BA, Chen R, Garcia JA, et al. (2014) The oxygen-rich postnata environment induces cardiomyocyte cell-cycle arrest through DNA damage response. Cell 157:565-579.

Rupert CE and Coulombe KL (2015) The roles of neuregulin-1 in cardiac development, homeostasis, and disease. Biomark Insights 10 (Suppl 1):1-9.

Saraswati S, Alfaro MP, Thorne CA, Atkinson J, Lee E, and Young PP (2010) Pyrvinium, a potent small molecule Wnt inhibitor, promotes wound repair and post-MI cardiac remodeling. PLoS One 5:e15521. 
Sasaki T, Hwang H, Nguyen C, Kloner RA, and Kahn M (2013) The small molecule Wnt signaling modulator ICG-001 improves contractile function in chronically infarcted rat myocardium. PLoS One 8:e75010.

Schulte G (2010) International union of basic and clinical pharmacology. LXXX. The class frizzled receptors. Pharmacol Rev 62:632-667.

Senyo SE, Steinhauser ML, Pizzimenti CL, Yang VK, Cai L, Wang M, Wu TD, Guerquin-Kern JL, Lechene CP, and Lee RT (2013) Mammalian heart renewal by pre-existing cardiomyocytes. Nature 493:433-436.

Shen H, Cui G, Li Y, Ye W, Sun Y, Zhang Z, Li J, Xu G, Zeng X, Zhang Y, et al. (2019) Follistatin-like 1 protects mesenchymal stem cells from hypoxic damage and enhances their therapeutic efficacy in a mouse myocardial infarction model. Stem Cell Res Ther 10:17.

Singh AP, Umbarkar P, Guo Y, Force T, Gupte M, and Lal H (2019) Inhibition of GSK-3 to induce cardiomyocyte proliferation: a recipe for in situ cardiac regeneration. Cardiovasc Res 115:20-30.

Slamon DJ, Leyland-Jones B, Shak S, Fuchs H, Paton V, Bajamonde A, Fleming T, Eiermann W, Wolter J, Pegram M, et al. (2001) Use of chemotherapy plus a monoclonal antibody against HER2 for metastatic breast cancer that overexpresses HER2. N Engl J Med 344:783-792.

Szibor M, Pöling J, Warnecke H, Kubin T, and Braun T (2014) Remodeling and dedifferentiation of adult cardiomyocytes during disease and regeneration. Cell Mol Life Sci 71:1907-1916.

Tseng AS, Engel FB, and Keating MT (2006) The GSK-3 inhibitor BIO promotes proliferation in mammalian cardiomyocytes. Chem Biol 13:957-963.

Uitterdijk A, Hermans KC, de Wijs-Meijler DP, Daskalopoulos EP, Reiss IK, Duncker DJ, Matthijs Blankesteijn W, and Merkus D (2016) UM206, a selective Frizzled antagonist, attenuates adverse remodeling after myocardial infarction in swine Lab Invest 96:168-176.

Uosaki H, Magadum A, Seo K, Fukushima H, Takeuchi A, Nakagawa Y, Moyes KW, Narazaki G, Kuwahara K, Laflamme M, et al. (2013) Identification of chemicals inducing cardiomyocyte proliferation in developmental stage-specific manner with pluripotent stem cells. Circ Cardiovasc Genet 6:624-633.

van den Borne SW, Diez J, Blankesteijn WM, Verjans J, Hofstra L, and Narula J (2010) Myocardial remodeling after infarction: the role of myofibroblasts. Nat Rev Cardiol 7:30-37.

Vermeulen Z, Segers VF, and De Keulenaer GW (2016) ErbB2 signaling at the crossing between heart failure and cancer. Basic Res Cardiol 111:60.

Wang J, Liu S, Heallen T, and Martin JF (2018) The Hippo pathway in the heart: pivotal roles in development, disease, and regeneration. Nat Rev Cardiol 15:672-684.

Wang S, Ye L, Li M, Liu J, Jiang C, Hong H, Zhu H, and Sun Y (2016) GSK-3 $\beta$ inhibitor CHIR-99021 promotes proliferation through upregulating $\beta$-catenin in neonatal atrial human cardiomyocytes. J Cardiovasc Pharmacol 68:425-432.

Wei K, Serpooshan V, Hurtado C, Diez-Cuñado M, Zhao M, Maruyama S, Zhu W, Fajardo G, Noseda M, Nakamura K, et al. (2015) Epicardial FSTL1 reconstitution regenerates the adult mammalian heart. Nature 525:479-485.
Witman N, Murtuza B, Davis B, Arner A, and Morrison JI (2011) Recapitulation of developmental cardiogenesis governs the morphological and functional regeneration of adult newt hearts following injury. Dev Biol 354:67-76.

Wo D, Peng J, Ren DN, Qiu L, Chen J, Zhu Y, Yan Y, Yan H, Wu J, Ma E, et al. (2016) Opposing roles of Wnt inhibitors IGFBP-4 and Dkk1 in cardiac ischemia by differential targeting of LRP5/6 and $\beta$-catenin. Circulation 134:1991-2007.

Woulfe KC, Gao E, Lal H, Harris D, Fan Q, Vagnozzi R, DeCaul M, Shang X, Patel S, Woodgett JR, et al. (2010) Glycogen synthase kinase-3beta regulates postmyocardial infarction remodeling and stress-induced cardiomyocyte proliferation in vivo. Circ Res 106:1635-1645.

Xie S, Fu W, Yu G, Hu X, Lai KS, Peng X, Zhou Y, Zhu X, Christov P, Sawyer L, et al. (2019) Discovering small molecules as Wnt inhibitors that promote heart regeneration and injury repair. J Mol Cell Biol DOI: 10.1093/jmcb/mjz023 [published ahead of print].

Xin M, Kim Y, Sutherland LB, Murakami M, Qi X, McAnally J, Porrello ER, Mahmoud AI, Tan W, Shelton JM, et al. (2013) Hippo pathway effector Yap promotes cardiac regeneration. Proc Natl Acad Sci USA 110:13839-13844.

Yang D, Fu W, Li L, Xia X, Liao Q, Yue R, Chen H, Chen X, An S, Zeng C, et al. (2017) Therapeutic effect of a novel Wnt pathway inhibitor on cardiac regeneration after myocardial infarction. Clin Sci (Lond) 131:2919-2932.

Ye B, Hou N, Xiao L, Xu Y, Boyer J, Xu H, and Li F (2015) APC controls asymmetric Wnt/ $\beta$-catenin signaling and cardiomyocyte proliferation gradient in the heart. $J$ Mol Cell Cardiol 89 (Pt B):287-296.

Yuan X and Braun T (2017) Multimodal regulation of cardiac myocyte proliferation. Circ Res 121:293-309.

Zak R (1973) Cell proliferation during cardiac growth. Am J Cardiol 31:211-219.

Zelarayán LC, Noack C, Sekkali B, Kmecova J, Gehrke C, Renger A, Zafiriou MP, van der Nagel R, Dietz R, de Windt LJ, et al. (2008) Beta-Catenin downregulation attenuates ischemic cardiac remodeling through enhanced resident precursor cell differentiation. Proc Natl Acad Sci USA 105:19762-19767.

Zhao B, Li L, and Guan KL (2010) Hippo signaling at a glance. J Cell Sci 123: 4001-4006.

Zhao L, Ben-Yair R, Burns CE, and Burns CG (2019) Endocardial Notch signaling promotes cardiomyocyte proliferation in the regenerating zebrafish heart through Wnt pathway antagonism. Cell Rep 26 (3):546-554.e5.

Zhao L, Borikova AL, Ben-Yair R, Guner-Ataman B, MacRae CA, Lee RT, Burns CG, and Burns CE (2014) Notch signaling regulates cardiomyocyte proliferation during zebrafish heart regeneration. Proc Natl Acad Sci USA 111:1403-1408.

Address correspondence to: Dr. W. Matthijs Blankesteijn, Department of Pharmacology and Toxicology, Cardiovascular Research Institute Maastricht, Maastricht University, P.O. Box 616, 6200MD Maastricht, The Netherlands. E-mail: wm.blankesteijn@maastrichtuniversity.nl 